IZA DP No. 8466

Early Retirement and Financial Incentives:

Differences Between High and Low Wage Earners

Rob Euwals

Elisabetta Trevisan

September 2014 


\title{
Early Retirement and Financial Incentives: Differences Between High and Low Wage Earners
}

\author{
Rob Euwals \\ CPB, Netspar and IZA \\ Elisabetta Trevisan \\ University of Padua, Netspar and CPB
}

Discussion Paper No. 8466

September 2014

\author{
IZA \\ P.O. Box 7240 \\ 53072 Bonn \\ Germany \\ Phone: +49-228-3894-0 \\ Fax: +49-228-3894-180 \\ E-mail: iza@iza.org
}

\begin{abstract}
Any opinions expressed here are those of the author(s) and not those of IZA. Research published in this series may include views on policy, but the institute itself takes no institutional policy positions. The IZA research network is committed to the IZA Guiding Principles of Research Integrity.

The Institute for the Study of Labor (IZA) in Bonn is a local and virtual international research center and a place of communication between science, politics and business. IZA is an independent nonprofit organization supported by Deutsche Post Foundation. The center is associated with the University of Bonn and offers a stimulating research environment through its international network, workshops and conferences, data service, project support, research visits and doctoral program. IZA engages in (i) original and internationally competitive research in all fields of labor economics, (ii) development of policy concepts, and (iii) dissemination of research results and concepts to the interested public.
\end{abstract}

IZA Discussion Papers often represent preliminary work and are circulated to encourage discussion. Citation of such a paper should account for its provisional character. A revised version may be available directly from the author. 
IZA Discussion Paper No. 8466

September 2014

\section{ABSTRACT \\ Early Retirement and Financial Incentives: Differences Between High and Low Wage Earners}

This paper investigates the impact of financial incentives on early retirement behaviour for high and low wage earners. Using a stylized life-cycle model, we derive hypotheses on the behaviour of the two types. We use administrative data and employ a linear random effects model to test the predictions. We exploit exogenous variation in the replacement rate over birth cohorts of workers who are eligible to a transitional early retirement scheme. The empirical results show that low wage earners are, as predicted by the model, more sensitive to financial incentives. This implies that low wage earners will experience a stronger incentive to continue working in an early retirement scheme with a low implicit tax rate.

JEL Classification: J16, J22, J61

Keywords: pensions, early retirement, labour market behaviour

Corresponding author:

Rob Euwals

CPB Netherlands Bureau for Economic Policy Analysis

P.O. Box 80510

2508 GM Den Haag

The Netherlands

E-mail: r.w.euwals@cpb.nl 


\section{Introduction}

Many countries are reforming their early retirement and pension schemes to guarantee the fiscal sustainability of the welfare system. In several countries, including Germany, Italy and the Netherlands, the reforms have led to a public debate on the differential impact on high and low wage earners. Low wage earners may be forced to continue working at older ages as they are in need of income, while high wage earners may have the resources to finance early retirement. This may be seen as unfair as low wage earners may have 'hazardous or arduous' jobs, possibly reducing the time during which retirement benefit can be enjoyed (Zaidi and Whitehouse, 2009). Optimal early retirement and pension institutions may include financial incentives to induce workers in good health to continue working (Cremer et al., 2004, 2008). For the assessment of the impact of such policy, it is useful to know how high and low wage earners react to such financial incentives.

Despite the extensive empirical literature, no study has investigated the difference in retirement behaviour between high and low wage earners. ${ }^{1}$ The novelty of this paper is based on three elements. First, we investigate both theoretically and empirically the early retirement choices and responses to financial incentives of high and low wage earners. Second, we use administrative data from the second largest pension fund in Netherlands (the health care fund PFZW, the former PGGM). The data contain reliable information on pension and early retirement rights of employees, and in particular we know the benefit level of each possible early retirement age. Third, we exploit a source of exogenous variation in replacement rates to identify the effect of financial incentives. The variation comes from a transitional early retirement scheme, which includes a reduction in replacement rates over successive birth cohorts. The precise knowledge of the benefit level at each possible retirement age, together with exogenous variation in these benefit levels improves measurements and identification of financial incentives over a large part of the aforementioned literature.

The empirical results confirm the predictions of the life-cycle model presented: low wage earners are more sensitive to financial incentives than high wage earners. A high cost of continuing to work in terms of utility, possibly because of hazardous work and a faster deterioration of health, does not reduce the higher sensitivity to financial incentives of low wage earners. So, financial incentives for continuing working, which may be part of an optimal design of early retirement institutions, may induce in particular low wage earners to postpone early retirement.

\footnotetext{
${ }^{1}$ The literature includes Lumsdaine and Mitchell (1999) and Gruber and Wise (2004). The latter study, which employs a structural approach, includes studies on Germany (Börsch-Supan et al., 2004), the United Kingdom (Blundell et al., 2004), Italy (Brugiavini and Peracchi, 2004) and the Netherlands (De Vos and Kapteyn, 2004). Studies which exploit a 'quasi-natural' experiment include Kruger and Pischke (1992), Baker and Benjamin (1999), Røed and Hangen (2003) and Euwals et al. (2010a).
} 
The paper is organized as follows. Section 2 describes briefly the model on high and low wage earners. Section 3 discusses early retirement in Netherlands and in particular in the health care sector. Section 4 presents the data and descriptive statistics. Section 5 describes the empirical strategy, while section 6 discusses the results. Section 7 provides some concluding remarks.

\section{Model on high and low wage earners}

We employ a stylized model to illustrate the potential impact of hazardous work on the reaction of high and low wage earners to financial incentives. The standard life cycle model shows that individuals retire at the moment the marginal utility of inactivity becomes equal to marginal productivity. Furthermore, individuals in poor health will retire earlier than individuals in good health. The sensitivity to financial incentives is however not clear upfront. Low wage earners may be more sensitive as their marginal utility to income is higher. Low skilled may also be less sensitive as they may experience a stronger disutility of work, making work activity costly in terms of utility.

We consider two types of individuals who differ in the wage level, i.e. $w_{H}>w_{L}$, with subscript $H$ for the high wage earners and $L$ for the low wage earners. We design the model such that it illustrates the impact of the curvature of the felicity function and the disutility of labour on early retirement behaviour. ${ }^{2}$ Furthermore, the modelling of the pension benefits formula takes in account the fact that the pension system could be actuarially fair or unfair, introducing a parameter $\delta$ capturing the level of actuarial fairness. In case of an actuarial unfair system the pension benefit is independent of the earning history $(\delta=1)$, and in case of a actuarial fair system the net present value of the pension benefit is equal to the net present value of the taxes $(\delta=0)$. In practise, most pension systems in the world are a mixture of the two extreme cases.

To illustrate how the financial incentives affect the retirement age for the two types of workers, we provide in tables 1 and 2 a numerical example. We first consider the case in which high and low wage earners differ in the wage level only. The other parameters are chosen such that individuals work a major part of their adult life. The simple model predicts that for the partly actuarial fair case, low wage earners work a larger part of their life than high wage earners (Table 1). The model shows that actuarial unfair system $(\delta=1)$ leads to early retirement.

The elasticities of retirement age $(z)$ with respect to the wage rate and the pension benefit level are larger for low wage earners. The interpretation is obvious as low wage earners are on the steep part of their utility function. That is, a marginal increase in consumptions leads to a large increase in marginal utility. Furthermore the elasticity with respect to the benefit level is particularly large in

\footnotetext{
${ }^{2}$ A detailed description of the model is presented in Appendix A.
} 
actuarial unfair system. The prediction is in line with the low participation of elderly in countries with a high implicit tax rate, including the Netherlands (Gruber and Wise, 2004, De Vos and Kapteyn, 2004).

Table 1: Elasticises in case individuals differ in wage only

\begin{tabular}{lllll}
\hline & Consumption & Retirement age & $\begin{array}{l}\text { Compensated } \\
\text { wage elasticity }\end{array}$ & Pension elasticity \\
\hline & c & e_c(z) w.r.t. w & & \\
& & & & \\
Partly actuarial fair $(\delta=0.5)$ & 1.705 & 0.152 & -0.024 \\
High wage earners & 0.861 & 0.873 & -0.050 \\
Low wage earners & & & 0.163 & -0.069 \\
Completely actuarial unfair $(\delta=1)$ & 1.665 & 0.832 & 0.216 & -0.301 \\
High wage earners & 0.820 & 0.799 & 0.495 & \\
\hline Low wage earners & & & & \\
\hline
\end{tabular}

Note: $u(c)=-c^{-\gamma}, R(z)=(1-z)^{-\alpha}$. Wages $w_{H}=2>w_{L}=1$ and parameters values $\gamma=0.5$ and $\alpha=0.05$ for both high and low wage earners.

Table 2: Elasticises in case individuals differ in wage and disutility of work

\begin{tabular}{lllll}
\hline Consumption & Retirement age & $\begin{array}{l}\text { Compensated } \\
\text { wage elasticity }\end{array}$ & Pension elasticity \\
\hline c & z & e_c(z) w.r.t. w & e(z) w.r.t. p
\end{tabular}

\begin{tabular}{|c|c|c|c|c|}
\hline \multicolumn{5}{|c|}{ Partly actuarial fair $(\delta=0.5)$} \\
\hline High wage earners & 1.705 & 0.856 & 0.152 & -0.024 \\
\hline Low wage earners & 0.788 & 0.769 & 0.290 & -0.100 \\
\hline \multicolumn{5}{|c|}{ Completely actuarial unfair $(\delta=1)$} \\
\hline High wage earners & 1.665 & 0.832 & 0.216 & -0.069 \\
\hline Low wage earners & 0.755 & 0.637 & 0.974 & -0.661 \\
\hline
\end{tabular}


The question now is whether differences in disutility of work can turn the results upside down. We consider the case in which high and low wage earners differ both in their wage rate and their disutility to work (i.e. $R_{L}(Z)>R_{H}(z)$ ). The low wage earners now work a smaller part of their life than high wage earners (Table 2).

The higher disutility of work for low wage earners does not make them less sensitive to financial incentives. Changes in financial conditions lead to sizable changes in behaviour. Moreover, the elasticity with respect to the benefit level in case of an actuarial unfair system becomes larger. This is again in line with the fact that in many European countries, of which many have an actuarial unfair early retirement system, in particular low wage earners retire early (OECD, 2013; Queisser and Whitehouse, 2006).

Clearly the choice of parameters values $\alpha$ and $\gamma$ in the utility and disutility functions affects the outcomes. The values have been chosen such that individuals work a major part of their adult live, a fact that is in line with labour market statistics. So other parameter values and other model specifications will of course lead to different results. ${ }^{3}$ Our prediction of low wage earners being more sensitive to financial incentives holds however under many different specifications as low wage earners are on the steep part of their utility function. Still there may be model specifications and parameter values for which this is not the case and in the end it is an empirical question.

\section{Early retirement in the Dutch health sector}

Identification of the impact of financial incentives on early retirement behaviour will be based on changes in early retirement conditions of workers in the health care sector. This section describes the early retirement reforms in the Netherlands and the way they affected health care sector workers.

\subsection{Early retirement reforms in the Netherlands}

Until about one decade ago, the financial incentive for an individual to continue working at old age was low in the Netherlands. Most sectors had a generous early retirement scheme during the 1980s and the 1990s. Workers with a career which met conditions on tenure within the sector, qualified for an actuarial unfair early retirement benefit (the so-called VUT) at age 60. The gross replacement rate of the benefit was about 80 percent of the last earned wage and continuing to work did not affect the replacement rate. So the implicit tax was 80 to 100 percent. The actuarial unfair schemes

\footnotetext{
${ }^{3}$ In particular, two elements may play a role: lifetime expectancy and time preference. In our model specification, lifetime is certain and it is the same for high and low wage earners, while time preference is not included. However, sensitivity analysis shows that lifetime expectancy and time preference have an impact on the optimal choice of consumption and retirement age, but the impact on the elasticises is limited.
} 
were considered highly responsible for the low participation rate of elderly during the 1980s and the 1990s (De Vos and Kapteyn, 2004).

Policy improved the incentives to continue working at old age. First, the stakeholders, i.e. the unions and the employer organizations, decided to reform the early retirement schemes starting from the end of 1990s onwards to guarantee the sustainability of the schemes. The new schemes would offer an actuarial fair early retirement benefit with a lower replacement rate. Actuarial fairness implies that postponement (advancement) of early retirement leads to an increase (decrease) in the benefit level and the net present value of the benefit is more or less independent of the age of retirement. ${ }^{4}$ The starting date of the transition to the new schemes varied by sector. Civil servants were the first to be confronted with changing early retirement conditions as the reform of their scheme started on April 1, 1997. Health care sector workers were the second group as the reform of their scheme started on January 1, 1999.

To ease the pain of the reform, most sectors installed a transitional arrangement. The reform was harsh for workers close to eligibility for the old scheme as the replacement rates of the new schemes were substantially lower. Workers close to eligibility and who participated continuously in a pension fund of a sector for a certain number of years were offered access to a more generous transitional scheme.

A second policy that improved the incentives to continue working was installed on January 1, 2006. The Dutch government decided to stop the fiscally favourable treatment of actuarial unfair early retirement schemes from that date onwards. A higher participation rate of elderly was an explicit policy goal and the government no longer wanted to subsidise schemes that discourage participation. The decision speeded the transition process as it was already decided to transform the schemes towards actuarial fair schemes. The speeding up was substantial; many sectors of industry are going to have an actuarial fair system in 2015.

\subsection{The way the reforms affected workers in the health care sector}

From January 1, 1999 onwards, health care sector workers had no access anymore to the actuarial unfair scheme (the so-called VUT). Instead, workers had access to the new actuarial fair benefit with a lower replacement rate (the so-called FLEX).

Workers have a claim on the new benefit on the first day of the month in which they become 60 years old. The benefit level at age 60 is 1.75 percent of the basic salary for each year of

\footnotetext{
${ }^{4}$ The actuarial adjustment is calculated on the basis of the time discount factor used by the pension fund; for the individual worker the adjustment may not be actuarial fair as the individual discount factor may be different.
} 
participation in the fund. This is equal to the number of working years in the sector as participation is mandatory. The new scheme is less attractive than the old one even for workers who have been working in the sector for 40 years as their replacement rate is 70 percent, while the old scheme offered a replacement rate of 80 percent. In case of advancement or postponement of early retirement, the level of the benefit is adjusted in an actuarially fair manner.

Workers close to age 60 had access to a transitional arrangement (the so-called OBU). The arrangement contains elements of the old and the new scheme. First, workers have access to OBU in case they have been working uninterrupted in the sector for the last ten years (a condition that held for the old scheme as well). Second, the scheme is actuarial unfair as continuing to work does not result in a higher benefit level. Note that the scheme became actuarial fair in 2006 because of government policy. Third, the scheme has a transitional nature as the replacement rate was brought back over time from 80 percent, the rate of the old scheme, to 70 percent, the rate of the new scheme. Workers born in 1939 or before got a replacement rate of 80 percent, workers born in 1940 got 79 percent, and further down workers born in 1948 got 71 percent. Workers born in 1949 and later had no access to transitional arrangement.

\section{The data}

The empirical analysis in this study is based on administrative data from the second largest pension fund in the Netherlands, the health care sector pension fund PFZW (former PGGM). The fund placed the administrative records of its participants for the years 1999-2007 at the disposal of Statistic Netherlands. The data is processed such that it can be merged to other administrative data available at Statistic Netherlands.

The administrative pension fund data is a yearly cross-section containing individual records of the participants of the fund. The data contains information on gender, date of birth, working hours, wages, tenure and pension and early retirement rights. The kind of occupation is not available in the data, but nevertheless we know that the occupations vary from nurses to medical doctors and include supporting activities like administration. Note that not all medical doctors are included in the data as many are self-employed. The number of observations in the dataset increases from 0.8 million in 1999 to 1.2 million in 2006 . The number of observations in the data increases over time for two reasons. The Dutch health sector is growing due to population growth and ageing, which leads to an increase in the demand for health care. Furthermore, the fund is expanding due to acquisition of firms that belong to the sector but that were not yet participating in the fund. 
Table 3: Descriptive statistics, age 15-64, 1999-2006 ${ }^{\text {(a) }}$

\begin{tabular}{|c|c|c|c|c|c|c|c|}
\hline & 1999 & 2000 & 2001 & 2002 & 2003 & 2005 & 2006 \\
\hline Observations & 787 & 881 & 808 & 1.158 & 1.032 & 1018 & 1109 \\
\hline Gender & $\%$ & & & & & & \\
\hline Female & 82 & 82 & 83 & 82 & 83 & 84 & 84 \\
\hline Male & 18 & 18 & 17 & 18 & 17 & 16 & 16 \\
\hline \multicolumn{8}{|l|}{ Age } \\
\hline$<20$ & 1 & 1 & 2 & 2 & 2 & 2 & 1 \\
\hline $20-24$ & 6 & 7 & 8 & 8 & 9 & 9 & 8 \\
\hline $25-29$ & 12 & 10 & 10 & 10 & 10 & 11 & 10 \\
\hline $30-34$ & 14 & 14 & 13 & 13 & 11 & 11 & 10 \\
\hline $35-39$ & 16 & 16 & 15 & 14 & 13 & 13 & 12 \\
\hline $40-44$ & 17 & 17 & 16 & 16 & 15 & 15 & 14 \\
\hline $45-49$ & 15 & 19 & 15 & 15 & 15 & 15 & 15 \\
\hline $50-54$ & 12 & 12 & 12 & 12 & 12 & 13 & 13 \\
\hline $55-49$ & 6 & 7 & 7 & 8 & 9 & 9 & 10 \\
\hline $60-65$ & 2 & 2 & 3 & 3 & 3 & 2 & 6 \\
\hline \multicolumn{8}{|l|}{ Working hours } \\
\hline 1-11 hours & 14 & 15 & 16 & 34 & 21 & 9 & 9 \\
\hline 12-23 hours & 31 & 30 & 29 & 23 & 27 & 27 & 28 \\
\hline 24-31 hours & 20 & 20 & 20 & 16 & 19 & 20 & 21 \\
\hline 32-35 hours & 11 & 11 & 12 & 9 & 12 & 12 & 12 \\
\hline 36 and more hours & 24 & 24 & 23 & 18 & 21 & 31 & 31 \\
\hline \multicolumn{8}{|l|}{ Tenure } \\
\hline 0-9 years & 61 & 59 & 60 & 56 & 55 & 57 & 52 \\
\hline $10-19$ years & 26 & 27 & 29 & 28 & 28 & 27 & 28 \\
\hline 20-29 years & 12 & 12 & 14 & 13 & 14 & 13 & 15 \\
\hline 30-39 years & 1 & 2 & 2 & 2 & 3 & 3 & 5 \\
\hline$>40$ years & 0 & 0 & 0 & 0 & 0 & 0 & 0 \\
\hline \multicolumn{8}{|c|}{ Fulltime salary $^{(\mathrm{b})} \quad$ thousands } \\
\hline Q10 & 15.4 & 15.7 & 16.4 & 16.9 & 18.0 & 18.9 & 19.4 \\
\hline Q25 & 17.9 & 18.4 & 19.2 & 19.8 & 21.2 & 22.3 & 22.8 \\
\hline Q50 & 22.0 & 22.6 & 23.8 & 24.5 & 26.6 & 27.9 & 28.4 \\
\hline Q75 & 26.6 & 27.5 & 28.9 & 30.2 & 32.5 & 33.9 & 34.3 \\
\hline Q90 & 31.7 & 32.9 & 34.6 & 36.4 & 38.9 & 40.9 & 41.7 \\
\hline
\end{tabular}

Source: administrative data of the pension fund of the health care sector, 1999-2006.

(a) Participants of the pension fund PFZW, the pension fund of the health care sector. The participants include former participants (so-called 'sleepers') and exclude PFZW and PGGM employees. The participants include, for example, nurses, social workers, and physicians employed by a hospital. The years 2004 and 2007 are not used as the data are incomplete for these particular years.

(b) The so-called 'pensionable' salary in gross terms.

We merge the administrative pension fund data to two other datasets. The first is the administrative municipality dataset (GBA), which is based on population registers. It contains demographic 
information like birth, marriage, local migration and mortality. The second is the administrative employment register dataset (SSB), which is based on the national employment insurance registers and on the Dutch tax registers. The registers contain information on working hours, salary and some firm information (see Euwals et al., 2010b, for details).

Table 3 presents descriptive statistics for the entire database. The health sector employs many parttime working women. This is due to the large number of nursing jobs within the sector. Furthermore, many individuals are between age 25 and 50. Only few individuals have tenure in the sector of more than 30 years, which is largely the result of a relatively young workforce. A minority of employees work fulltime, whereby the fraction has increased from about one out of four in 1999 to about one out of three in 2006. The gross fulltime wage ranges from 20 to 42 thousand euro per year in 2006. Wage inequality has increased over time. The gross fulltime wage of the upper quintile (q90) has increased with 32 percent while for the lowest quintile (q10) it has increased with 26 percent.

During the first year of observation, the year 1999, about 95 percent of workers born before 1949 is eligible for the transitional scheme. Most of them have access at age 60; only a small percentage of workers have access at age 61 or later (see also Euwals et al., 2010b). The later access is partly the result of the requirement to be working in the sector for at least 10 years. Selection may also play a role however. Workers eligible at age 60 may have decided to continue working and are therefore eligible at age 61 . The number of employees who do not satisfy the requirements for the transitional arrangement is higher in 2006. This may again be a selection effect as to be eligible one needed to be employed in the sector in 1998.

Individuals who are and are not eligible to the transitional scheme differ in several aspects. The major difference is represented by tenure distribution; the majority of the 'non-eligible' has tenure lower than ten years. The two groups differ in other aspect as well. Many of the non-eligible individuals are women, work part-time for one to eleven hours per week, and have lower wages.

\subsection{Early retirement behaviour in the health care sector}

Descriptive statistics do not reveal a substantial difference in early retirement behaviour between high and low wage earners. The hazard rate into early retirement plotted in figure 1 is rather similar for both types of workers. Many workers have access to the transitional early retirement scheme at age 60 and most of them take that opportunity. ${ }^{5}$ This result is in line with previous research on the

\footnotetext{
${ }^{5}$ We consider workers who have access to the transitional arrangement only; workers without access may have a much lower labour market attachment or may have substantial pension rights outside the health sector.
} 
impact of the old early retirement scheme (Kerkhofs et al., 1999, De Vos and Kapteyn, 2004, Heyma, 2004).

The scheme of the health care sector offers the opportunity of part-time retirement at age 58 and 59, but this opportunity does not seem popular. Workers who access to an early retirement benefit at age 60 can retire at age 58 (59) and receive 50 percent of the benefit during ages 58 to 61 (59 and 60). From age 62 (61) onwards they receive the full 100 percent of the benefit. The take up of parttime early retirement does not seem to differ between high and low wage earners as well.

\section{Figure 1: hazard rate for early retirement, high (left) and low (right) wage earners}

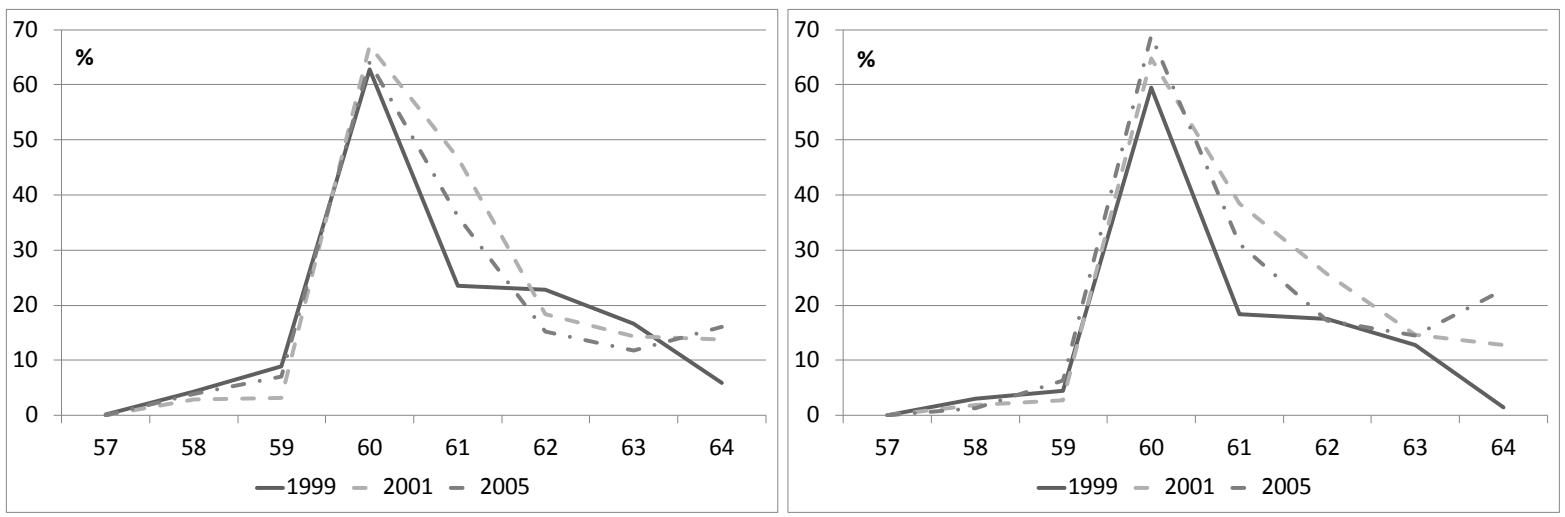

Source: administrative data of the pension fund of the health care sector, 1999-2006, own calculations.

Note: Probability of early retirement conditional on being employed at year $t-1$, Kaplan-Maier estimator for workers eligible to the transitional scheme. High and low wage earners are defined on the basis of a fixed effects model described in section 4 .

The decrease in the replacement rate of the transitional arrangement may have led to a decreasing conditional probability (hazard rate) to retire, but this trend does not seem to be present in figure 1 . The conditional probability to retire early actually seems to increase over time for both high and low wage earners. The reason may however be that the fraction of workers that is eligible to the transitional scheme at age 60 also increases over time. The empirical analysis of the next section will take the exact timing of the early retirement rights into account and it will use it to identify the impact of the financial incentives.

\section{Empirical strategy}

We only exploit the exogenous variation in the replacement rate over birth cohorts of workers who are eligible to the transitional scheme. We use the empirical model of Stock and Wise (1990). We select working individuals between age 57 and 63 years old and who are eligible to the transitional scheme. 


\subsection{Definition of high and low wage earners}

The study identifies the differences in the impact of financial incentives on early retirement behaviour between high and low wage earners. Another obvious choice to distinguish between groups would have been on the basis of educational attainment, but unfortunately this is not observed in the administrative data. We propose a definition that takes the life cycle into account by correcting the wage for demographic characteristics, so taking into account that wages are relatively low at young ages.

To distinguish between high and low skilled workers we use the variable on the fulltime wage. In order to maintain the same composition of the two groups over all periods and to have a good approximation of permanent or life-cycle income we run a fixed effect model on the fulltime wage We use the following equation:

$$
W_{i t}=\alpha_{i}+X_{i t} \beta+\delta_{t}+\varepsilon_{i t}
$$

where $W_{i t}$ is the fulltime wage, $\alpha_{i}$ is the individual fixed effect and $\delta_{t}$ is the time effect. The vector $X_{i t}$ contains demographic and employment characteristics including number of children, marital status, number of jobs, tenure and the unemployment rate. Next, we look at the distribution of the individual fixed effect and we define high skilled workers as individuals who have fixed effect higher than the median and low skilled workers as individuals who have fixed effect lower than the median.

The estimation results may be sensitive to the choice of the cut-off point to distinguish between the high and low wage earners. For this reason we performed some sensitivity analyses, using the $\left(25^{\text {th }}\right.$, $\left.75^{\text {th }}\right)$ percentile and the $\left(10^{\text {th }}, 90^{\text {th }}\right)$ percentile as cut-off points. The conclusions from these analyses are in line with the results presented in the paper.

\subsection{Estimation strategy}

The variable of interest if the probability to retire in year $t+1$ given that the individual works in year $t$. Using a Linear Probability Model with random effects, we estimated the following equation:

$$
P\left(y_{i t+1}=\text { retired } \mid y_{i t}=\text { employed }\right)=X_{i t} \beta+S S W_{i t} \gamma+F I_{i t} \delta+O V W_{i t} \varphi+u_{i}+\varepsilon_{i t}
$$


where $X_{i t}$ contains demographic and employment characteristics and the unemployment rate. ${ }^{6}$ The variable $S S W_{i t}$ represents the Social Security Wealth, $F I_{i t}$ represents the financial incentive for the price (wage) effect and $O V W_{i t}$ represents the Option Value to Wait. Note that because of the administrative data we know exactly the benefit level at each possible retirement age. This improves the measurement and identification of the financial incentives substantially over a large part of the literature discussed in the introduction. We use two different measures of financial incentives, the implicit tax on continuing to work and the peak value (Stock and Wise, 1990).

The Social Security Wealth is the Net Present Value of the early retirement and pension benefits $\left(B_{t}^{E R}, B_{t}^{P}\right)$ at time $t$ in case the individual would retire at age $R$ :

$$
N P V_{i t}(R)=\sum_{s=R}^{64} \gamma_{t} \delta^{(s-t)} B_{t}^{E R}(R)+\sum_{s=65}^{T} \gamma_{t} \delta^{(s-t)} B_{t}^{P}(R)
$$

where $\delta$ is the discount factor and $\gamma_{t}$ is the survival probability. ${ }^{7}$ Each individual is eligible to the new actuarial fair scheme (FLEX) at any age above age 55, and becomes eligible to the transitional scheme (OBU) at age $a_{i}^{O B U}$. Therefore $S S W_{i t}$ is equal to:

$$
S S W_{i t}=I\left(a_{i t}<a_{i}^{O B U}\right) S S W_{i t}^{F L E X}+I\left(a_{i t} \geq a_{i}^{O B U}\right) S S W_{i t}^{O B U}
$$

The implicit tax of postponing retirement from year $t$ to year $t+1$ is given by:

$$
I T_{i t}=-\frac{S S W_{i t+1}-S S W_{i t}}{W_{i t+1}}
$$

where $W_{i t+1}$ is the wage at year $t+1 .^{8}$ The peak value is the maximum difference in social security wealth when retiring at future ages and retiring at current age:

$$
P V_{i t}=\max \left(S S W_{u i}-S S W_{i t}\right) \quad u=t+1, \ldots, M
$$

where $M$ is the year in which the individual reaches the mandatory retirement age of 65 . Finally, the option value to wait gives the gain of postponing retirement:

\footnotetext{
${ }^{6}$ The demographics include gender, marital status, nationality and number of children, while the employment characteristics include the number of jobs and tenure in the sector.

${ }^{7}$ The time discount rate of $3 \%$ and the survival table are provided by the pension fund of the health care sector.

${ }^{8}$ The wage at $t+1$ in the implicit tax formula is given by pensionable salary in $t+1$ used by the pension fund to calculate the pension benefit level.
} 


$$
O V W_{i t}= \begin{cases}0 & \text { if } a_{i t} \geq a_{i}^{O B U} \\ S S W_{i t s}^{O B U}-S S W_{i t}^{F L E X} & \text { if } a_{i t}<a_{i}^{O B U}\end{cases}
$$

where $S S W_{i t s}^{O B U}$ it the net present value of social security wealth for individual $i$ at year $t$ and reaching eligibility for the (generous) transitional OBU scheme in year $s$.

Using the empirical model of equation (2), we test whether low wage earners react stronger to financial incentives represented by the social security wealth (the income or pension effect), the financial measure for the return to continue working (the price or wage effect) and the option value to wait. So we expect to find larger parameters estimates, representing the size of the reaction to financial incentives, for low wage earners.

Note that the computation of the net present value of the early retirement and pension benefits, which underlies the financial incentives, does not take potential differences in lifetime expectancy and time preference into account. Empirical evidence suggests that low wage earners have a lower life expectancy and higher time discount rate. ${ }^{9}$ The potential overestimation of the net present value for low wage earners leads to an underestimation of the parameters for this group. We nevertheless decide to test our hypotheses on the basis of these assumptions as we have no information on the true life expectancy and time discount rate and the results give a lower bound for the true difference between high and low wage earners.

\section{Results}

On the basis of the theoretical model described in section 2, we expect low wage earners to be more sensitive to financial incentives than high wage workers. We use the empirical model of the previous section to test the hypothesis. The identification strategy exploits the change in the replacement rate of the transitional scheme over birth cohorts. Table 4 presents the estimation results.

The effect of Social Security Wealth (SSW) can be considered as a measure of the income effect. The empirical literature reports a small but significant effect. We find that for high wage earners the impact of the SSW is small and not always significant. For low wage earners, we find a more substantial and significant effect. An increase in SSW with 22,000 euro (the median wage for low wage earners) leads to an increase of the conditional probability to retire of 1.0 to 0.4 percentage point for the model with the implicit tax or peak value respectively. This implies a decrease of early retirement age of one month or half a month. The income effect is small, a result that is in line with overview articles like Gruber and Wise (1994) and Lumsdaine and Mitchel (1999). Moreover,

\footnotetext{
${ }^{9}$ See, for example, Kalwij et al. (2013).
} 
Krueger and Wise (1992) find that a reform in the US state pension did not affect labour supply, indicating a zero wealth effect, Joulfaian and Wilhelm (1994) find that inheritances have a modest impact on retirement decisions of older men, while Imbens et al. (2001) find that lottery winners consume about $11 \%$ of their winnings in the form of reduced labour earnings.

Table 4: Conditional probability of early retirement, marginal effects

\begin{tabular}{|c|c|c|c|c|c|c|c|c|}
\hline \multirow[b]{2}{*}{ OVW } & \multicolumn{2}{|c|}{ High wage earners } & \multicolumn{2}{|c|}{ Low wage earners } & \multicolumn{2}{|c|}{ High wage earners } & \multicolumn{2}{|c|}{ Low wage earners } \\
\hline & -0.018 & $* * *$ & -0.208 & $* * *$ & -0.011 & $* *$ & -0.123 & $* * *$ \\
\hline & $(0.004)$ & & $(0.011)$ & & $(0.005)$ & & $(0.012)$ & \\
\hline \multirow[t]{2}{*}{ SSW } & -0.001 & & 0.047 & $* * *$ & -0.002 & $* * *$ & 0.017 & $* * *$ \\
\hline & $(0.001)$ & & $(0.003)$ & & $(0.001)$ & & $(0.004)$ & \\
\hline \multirow[t]{2}{*}{ Implicit tax } & 0.030 & $* * *$ & 0.050 & $* * *$ & & & & \\
\hline & $(0.003)$ & & $(0.003)$ & & & & & \\
\hline \multirow[t]{2}{*}{ Peak Value } & & & & & -0.045 & $* * *$ & -0.814 & $* * *$ \\
\hline & & & & & $(0.010)$ & & $(0.033)$ & \\
\hline \multirow[t]{2}{*}{ Female } & 0.012 & $* * *$ & 0.052 & $* * *$ & 0.011 & $* * *$ & 0.035 & $* * *$ \\
\hline & $(0.003)$ & & $(0.005)$ & & $(0.003)$ & & $(0.005)$ & \\
\hline \multirow[t]{2}{*}{ Dutch } & 0.014 & $* * *$ & 0.004 & & 0.014 & $* * *$ & 0.005 & \\
\hline & $(0.004)$ & & $(0.004)$ & & $(0.003)$ & & $(0.004)$ & \\
\hline \multirow[t]{2}{*}{ Children } & -0.009 & $* * *$ & -0.014 & $* * *$ & -0.010 & $* *$ & -0.014 & $* * *$ \\
\hline & $(0.003)$ & & $(0.003)$ & & $(0.003)$ & & $(0.003)$ & \\
\hline \multirow[t]{2}{*}{ Married } & 0.007 & $* *$ & 0.019 & $* * *$ & 0.007 & $* *$ & 0.018 & $* * *$ \\
\hline & $(0.003)$ & & $(0.003)$ & & $(0.003)$ & & $(0.003)$ & \\
\hline \multirow[t]{2}{*}{ Number of jobs } & 0.001 & & -0.015 & $* * *$ & 0.001 & & -0.015 & $* * *$ \\
\hline & $(0.004)$ & & $(0.003)$ & & $(0.004)$ & & $(0.003)$ & \\
\hline \multirow[t]{2}{*}{ Tenure } & 0.000 & & -0.002 & $* * *$ & 0.000 & & -0.001 & $* * *$ \\
\hline & $(0.001)$ & & $(0.000)$ & & $(0.000)$ & & $(0.000)$ & \\
\hline \multirow[t]{2}{*}{ Age 57} & -0.335 & $* * *$ & -0.332 & $* * *$ & -0.351 & $* * *$ & -0.355 & $* * *$ \\
\hline & $(0.006)$ & & $(0.004)$ & & $(0.006)$ & & $(0.004)$ & \\
\hline \multirow[t]{2}{*}{ Age 58} & -0.359 & $* * *$ & -0.342 & $* * *$ & -0.373 & $* * *$ & -0.348 & $* * *$ \\
\hline & (0.004) & & $(0.004)$ & & $(0.004)$ & & $(0.004)$ & \\
\hline \multirow[t]{2}{*}{ Age 60} & -0.243 & $* * *$ & -0.246 & $* * *$ & -0.249 & $* * *$ & -0.240 & $* * *$ \\
\hline & (0.010) & & $(0.007)$ & & $(0.010)$ & & $(0.007)$ & \\
\hline \multirow[t]{2}{*}{ Age 61} & -0.262 & $* * *$ & -0.245 & $* * *$ & -0.268 & $* * *$ & -0.243 & $* * *$ \\
\hline & (0.013) & & $(0.008)$ & & $(0.013)$ & & $(0.008)$ & \\
\hline \multirow[t]{2}{*}{ Age 62} & -0.327 & $* * *$ & -0.308 & $* * *$ & -0.331 & $* * *$ & -0.309 & $* * *$ \\
\hline & (0.018) & & $(0.010)$ & & $(0.018)$ & & $(0.010)$ & \\
\hline \multirow[t]{2}{*}{ Unempl. rate } & -0.013 & $* * *$ & -0.004 & $* * *$ & -0.013 & $* * *$ & -0.005 & $* * *$ \\
\hline & $(0.001)$ & & $(0.001)$ & & $(0.001)$ & & $(0.001)$ & \\
\hline
\end{tabular}

Note: Standard errors in parentheses. ${ }^{*}, * *$ and ${ }^{* * *}$ means significance level at $10 \%, 5 \%$ and $1 \%$ respectively. Table presents the marginal effects of the estimation of a linear random effect model where the outcome variable is the probability to retirement conditional on employment at year $t-1$. 
The variables Option Value to Wait (OVW), Implicit Tax (IT) and Peak Value (PV) could be considered as measures of the price effect. The empirical literature discussed in the introduction reports a substantial and statistically significant effect on the decision to retire. The OVW has a negative and highly significant effect on retirement. The effect is substantially larger for low wage earners. In other words, a high reward on waiting for retirement lowers the probability to retire the next year in particular for low wage earners.

The implicit tax (IT) has a positive and significant effect: a high implicit tax on continuing to work leads to a high probability of retiring next year. A change from a completely actuarial fair system (i.e. an implicit tax of zero) to a completely actuarial unfair system (i.e. an implicit tax of 1) implies an increase in the conditional probability of 3 percentage points for high and 5 percentage points for low wage earners. The peak value has a strongly negative and highly significant effect. For low wage earners, a decrease of the peak value of 22,000 euro (that is roughly similar to a change in the implicit tax from zero to one) implies an increase in the conditional probability of retirement of 18 percentage points. This implies a decrease in the early retirement age of about one year. The size of the price (wage) effect may seem large, but the statistically and economically significant price effect is in line with overview articles like Gruber and Wise (1994) and Lumsdaine and Mitchel (1999). More recently, Ash et al. (2005) and Coile and Levine (2007) find a significant price effect as well. ${ }^{10}$

The differences in the impact of the financial variables (i.e., SSW, OVW, IT and PV) on high and low wage earners are statistically significant. As mentioned before, these variables are computed assuming the same survival probability and the same discount rate for both groups. Given the definition of these variables, different survival probability and discount rate for the two groups would have a 're-scaling' effect on SSW (and consequently on other variables) widening the differences between high and low wage earners. Therefore, our results can be considered as a lower bound for the difference between high and low wage earners.

Considering the other variables it turns out that individuals having children and individuals who have more than one job are less likely to retire next year. Furthermore, women, married and natives are more likely to retire earlier. The modal retirement age, independently from the financial incentives, turn out to be 60 years. The fact that financial variables do not fully explain a peak in the retirement probability at a certain age is a common finding in the empirical literature and hints at

\footnotetext{
${ }^{10}$ Ash et al. (2005) report that an additional US\$10,000 of expected pension wealth for continued work decreases the retirement rate by 4 percent whereby the average retirement age from age 55 onwards is about 20 percent and the average annual salary is about 45,000 US\$. Coile and Gruber (2007) report a similar parameter estimate for the peak value, whereby one should note these authors express the peak value in units of US\$100,000.
} 
the fact that other aspects of behaviour than rational financial decision making play an important role (Van Erp et al., 2013).

\section{Conclusion}

This paper investigates the impact of financial incentives on early retirement behaviour of high and low wage earners. Using a stylized life-cycle model we derive empirical implications on the behaviour of the two types. The model predicts that low wage earners should be more sensitive to financial incentives than high wage earners.

We use administrative pension fund data from the Dutch health sector to test the hypothesis. In order to identify the effect of financial incentives on early retirement, we employ a linear random effect model. We look at the early retirement choices of individuals eligible to a transitional early retirement scheme. The empirical analysis exploits a gradual change in the replacement rate over successive birth cohorts. We use direct measures of financial incentives like Social Security Wealth, the Option Value to Wait to become eligible, Implicit Tax and Peak Value. The precise knowledge of the benefit level at each possible retirement age, which is available because of the administrative data, together with the exogenous variation in these benefit levels improve measurement and identification of the impact of financial incentives on early retirement behaviour over a large part of the literature.

The empirical results show that low wage earners are more sensitive to financial incentives than high wage earners. The difference in behaviour is substantial for almost all measures of financial incentives. Both the income effect (measured by social security wealth) and the price effect (measured by the peak value and the option value to wait) are substantially larger in size for low wage earners.

An optimal early retirement scheme may include an early retirement option from a certain age onwards with an actuarial unfair adjustment of the benefit level in case the individual decides to continue working (Cremer et al. 2004, 2008). The early retirement option serves as an insurance against unobservable health shocks. In such a scheme workers experience a financial incentive to continue working. Our results imply that in such a scheme in particular low wage earners will experience a strong incentive to continue working. In the public debate this may not be expected as the outcome from an optimal scheme, in particular as special pensions for workers with 'hazardous' work are common practice in many countries (Zaidi and Whitehouse 2009).

Many questions are still open for future research, in particular on the exact impact of financial incentives. The model used in this study do not allow for liquidity constraints and short-sighted or irrational behaviour. From theory we know that liquidity constraints may affect high and low wage 
earners in a different way. High wage earners may experience such constraints early in life as they start to work late and they have steep wage profiles. Low wage earners may experience liquidity constraints later in life as they may want to borrow against their social security rights. The latter liquidity constraints may however result from short-sighted or irrational behaviour, which may occur among low wage earners more often. On the empirical side there exit intriguing challenges as well. The Dutch 2006 policy reform, for example, will offer challenging opportunities to identify the causal impact of financial incentives on retirement behaviour in the upcoming years.

\section{Acknowledgements:}

The authors thanks Rob Alessie, Hans Bloemen, Peter Kooiman, Adrie Moons, Giacomo Pasini, Pierre Pestieau, Arthur van Soest, Daniel van Vuuren, Bas ter Veel, Matthew Weikfield and participant of CPB, MEA and Netspar seminars, the DIW conference on Ageing, Savings and Retirement, ESPE 2010, EALE 2011 and BOMOPAV 2012 for comments. Stichting Instituut GAK is acknowledged for the provision of financial support, while PGGM/PFZW and Statistics Netherlands are acknowledged for the provision of the data. 


\section{References}

Asch, B., Haider S. and Zissimopoulos, J. (2005) Financial Incentives and Retirement: Evidence from Federal Civil Service Workers, Journal of Public Economics, 89: 427-440.

Baker, M. and Benjamin, D. (1999). Early Retirement Provisions and the Labor Force Behavior of Older Men: Evidence from Canada. Journal of Labor Economics, 17: 724-756.

Blundell, R., Meghir C., Smith, S. (2004). Pension Incentives and the Patterns of Retirement in the United Kingdom. In: Gruber J. and Wise D. (eds), Social Security Programs and Retirement Around the World: Micro Estimations, University of Chicago Press, Chicago: 643-689.

Börsch-Supan, A., Schnabel, R., Kohnz, S. and Mastrobuoni, G. (2004). Micro-modelling of Retirement Decisions in Germany. In: Gruber J. and Wise D. (eds), Social Security Programs and Retirement Around the World: Micro Estimations, University of Chicago Press, Chicago: 285-343.

Brugiavini, A. and Peracchi, F. (2004). Micro-modelling of Retirement Behaviour in Italy. In: Gruber J. and Wise D. (eds), Social Security Programs and Retirement Around the World: Micro Estimations, University of Chicago Press, Chicago: 345-397.

Cremer, H., Lozachmeur, J., Pastieau, P. (2004). Social Security, Retirement Age and Optimal Income Taxation. Journal of Public Economics, 88: 2259-2281.

Cremer, H., Lozachmeur, J., Pastieau, P. (2008). Social Security and Retirement Decision. A Positive and a Normative Approach. Journal of Economic Surveys, 22(2): 213-237.

Coile, C., and Levine, P. 2007, Labor market shocks and retirement: Do government programs matter? Journal of Public Economics, 91: 1902-1919.

De Vos, K. and Kapteyn, A. (2004). Incentives and Exit Routes to Retirement in the Netherlands. In: Gruber J. and Wise D. (eds), Social Security Programs and Retirement Around the World: Micro Estimations, University of Chicago Press, Chicago: 461-498.

Euwals, R., de Mooij, R., van Vuuren, D. (2009). Rethinking Retirement. CPB Special Publication 80.

Euwals, R., van Vuuren, D., Wolthoff, R. (2010a). Early Retirement Behaviour in the Netherlands. De Economist, 158(3): 209-236.

Euwals, R., Trevisan, E., van Vuren, A. (2010b). Labour Market Exit in the Health Care Sector. First Results from Administrative Data. Netspar Discussion Paper, No. 03-2010-016. 
Gruber, J. and Wise, D. (2004). Social Security Programs and Retirement Around the World: Micro Estimations, University of Chicago Press, Chicago.

Heyma, A. (2004). A Structural Dynamic Analysis of Retirement Behaviour in the Netherlands. Journal of Applied Econometrics, 19:739-759.

Imbens, G., Rubin D. and Sacerdote B. (2001) Estimating the Effect of Unearned Income on Labor Supply, Earnings, Savings and Consumption: Evidence from a Sample of Lottery Players, American Economic Review, 91(4): 778-794.

Joulfaian, D. and Wilhelm M. (1994). Inheritance and Labor Supply, Journal of Human Resources, 29(4): 1205-1234.

Kalwij, A., Alessie, R., Knoef, M. (2013). The Associations Between Individual Income and Remaining Life Expectancy at the Staturory Retirement Age of 65 in the Netherlands. Demography, 50(1): 181-206.

Kerkhofs, M., Lindeboom, M., Theeuwes, J. (1999). Retirement, Financial Incentives and Health. Labour Economics, 6: 203-227.

Krueger, A. and Pischke, J. (1992). The Effect of Social Security on Labour Supply: A Cohort Analysis of the Notch Generations. Journal of Labor Economics, 10: 412-437.

Lumsdaine, R. and Mitchell, O. (1999). New Developement in the Economic Analysis of Retirement. In: Ashenfelter O. And Card D. (eds), Handbook of Labour Economics, Elsevier, Amsterdam. Vol. 3: 3261-3307.

OECD (2013). Pension at Glance 2013: OECD and G20 Indicators. OECD Publishing. http://dx.doi.org/10.1787/pension_glance-2013-en.

Røed, K. and Hangen, F. (2003). Early Retirement and Economic Incentives: Evidence From a Quasi-Natural Experiment. Labour,17: 203-228.

Stock, J.H. and Wise, D.A. (1990). Pension, the Option Value to Work, and Retirement. Econometrica, 58(5): 1151-1180.

Queisser, M. and Whitehouse, E.R. (2006). Neutral or Fair? Actuarial Concepts and Pension System Design. OECD Social, Employment and Migration Working Papers, N. 40. OECD Publishing, http://dx.doi.org/10.1787/351382456457.

Van Erp, F., N. Vermeer and van Vuuren, D. (2013) Non-Financial Determinants of Retirement, Netspar Panel Paper 34.

Zaidi, A. and Whitehouse, E.R. (2009). Should Pension Systems Recognise "Hazardous and Ardour Works”?. OECD Social, Employment and Migration Working Paper, No. 91, OECD Publishing. 


\section{Appendix A: The model}

Let us consider two types of individuals who differ in the wage level, i.e. $w_{H}>w_{L}$, with subscript $H$ for the high wage earner and $L$ for the low wage earner. Each of them has an instantaneous utility function $U_{t}$ at age $t$ in which consumption $c_{t}$ and labour $l_{t}$ are separable:

$$
U_{t}=u\left(c_{t}\right)-r_{t} V\left(l_{t}\right)
$$

where the utility functions $u$ and $V$ fulfil the usual assumptions. The intensity of labour disutility $r_{t}$ increases with age. We assume separability, concavity of the instantaneous utility functions, perfect capital markets and certain lifetime such that each individual sets the level of consumption equal in all periods. As we ignore the intensive margin of labour supply, we additionally assume $l=l_{t}$ to be time invariant and equal to one ${ }^{11}$. We assume individuals have no liquidity constraints. ${ }^{12}$ The model reduces to a static model, and the choice is between the length of working life $z$ and the life cycle consumption $c$. Since consumption and labour supply are time invariant, lifetime utility can be written as.

$$
U=h u(c)-R(z)(9)
$$

with life span $h$ and retirement age $z$, and where:

$$
R(z)=\int_{0}^{z} r_{t}
$$

The life time budget constraint is given by:

$$
h c=z w-T(w, z)
$$

with wage rate $w$ and $T(w, z)$ is the difference between total tax payment and total retirement benefits.

$$
T(w, z)=z \tau(w)-(h-z) p(z)
$$

where $\tau(w)$ is the payroll tax and $p(z)$ is the level of the pension benefit. The benefit may depend on the length of the working life $z$ through the pension benefit formula. Considering that the pension system could be actuarially fair or unfair, we define $p(z)$ as follow:

$$
p(z)=\delta p_{0}+(1-\delta) \frac{z \tau(w)}{(h-z)}
$$

\footnotetext{
${ }^{11}$ This assumption play an important role in the optimal taxation literature (Cremer et al. 2004, 2008). In our case, it is not a restrictive assumption because the disutility of work depends on $z$.

${ }^{12}$ This assumption guarantees consistency with the empirical model which is based on Stock and Wise (1990).
} 
where $\delta$ represents the level of actuarial fairness. In case of an actuarial unfair system the pension benefit is independent of the earning history $(\delta=1)$ and in case of an actuarial fair system the net present value of the pension benefit is equal to the net present value of the taxes $(\delta=0)$. Substituting the term in $T(w, z)$, the budget constraint can be rewritten as follows:

$$
h c=z\left(w-\delta\left(\tau(w)+p_{0}\right)\right)+\delta p_{0}
$$

The first order conditions with respect to $c$ and $z$ lead to the marginal rate of substitution between $c$ and $z$ :

$$
M R S_{c, z}=\frac{R^{\prime}(z)}{u^{\prime}(c)}=w-\delta\left(\tau(w)+p_{0}\right)
$$

where the right-hand side of the equation represents the marginal net wage, whereby $\delta(\tau(w)+$ $\left.p_{0}\right)=T_{z}^{\prime}(w, z)$ represents the implicit tax on retirement. Individuals continue working until the marginal disutility of working is not compensated anymore by the marginal utility of additional income generated by working. In general, the high wage earners has a higher MRS, meaning that she works and consumes more that the low wage earner. When the two types differ also in the disutility of work (i.e., $R_{H}^{\prime}(z)<R_{L}^{\prime}(z)$ ) the comparison between the two marginal rates of substitutions is less clear. For $\delta>0$ (when the pension system is at least partly actuarially fair) there is a downward bias of the optimal retirement age for both types. This insight is confirmed by the research discussed in the introduction.

In order to derive the different sensitivity of the two types to financial incentives, we need to calculate elasticises of retirement age $(z)$ with respect to the wage rate $(w)$ and the level of the pension benefit $(p)$. These elasticises can be derived with implicit differentiation, but it is however not possible to determine which type of worker is more sensitive to the financial incentives coming from the wage level (price effect) and the pension benefit level (which is partly an income effect). In order to illustrate how the financial incentives affect the retirement age for the two types of workers a numerical example is provided in section 2. 